Civil Engineering

Volume 168 Issue CE6

Wearable simulations for ill-health conditions in construction

Gibb, Cook, Nyateka et al.
Proceedings of the Institution of Civil Engineers Civil Engineering 168 November 2015 Issue CE6 Pages 51-56 http://dx.doi.org/10.1680/cien. 14.00055 Paper 1400055

Received 07/07/2014_Accepted 27/04/2015

Published online: 19/08/2015

Keywords: health \& safety/safety \& hazards/

management

ICE Publishing: All rights reserved
,

\title{
Wearable simulations for ill-health conditions in construction
}

1 Alistair Gibb PhD, CEng, MICE, MCIOB Professor, School of Civil and Building Engineering, Loughborough University, UK

2. Sharon Cook MA Senior Lecturer, Loughborough Design School, UK

3 Netsai Nyateka MSc Researcher, School of Civil and Building Engineering, Loughborough University, UK
4 Phil Bust PhD, MIEHF

Researcher, School of Civil and Building Engineering, Loughborough University, UK

5 Wendy Jones PhD, RN, SPCHN(OH), MIEHF Researcher, School of Civil and Building Engineering, Loughborough University, UK

6 Aoife Finneran PhD, BEng, MIES

Researcher, School of Civil and Building Engineering, Loughborough University, UK
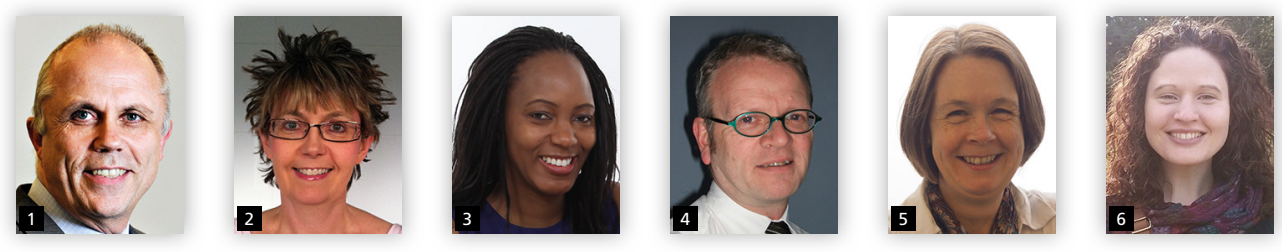

Occupational ill health and wellbeing is a significant challenge for workers in the civil engineering and construction sectors. The symptoms of many ill-health conditions become more severe over time and minor aches and pains in a young worker can develop into serious problems the older they get. Health and safety training has increased in recent years and site inductions are now ubiquitous. However, formal training methods seem to have little effect. Evidence-based, wearable simulations for common construction ill-health conditions have been developed from over $\mathbf{2 0}$ years of university-based research. The simulations provide a learning experience for dermatitis, hand-arm vibration syndrome, musculoskeletal disorders, noise-induced hearing loss and respiratory disorders and are being trialled with young apprentices aiming to change their attitudes and behaviours.

\section{Occupational ill health in construction}

Occupational illnesses are a significant problem for the UK construction industry. The 2011/2012 UK Labour Force Survey estimated that 74000 people whose current or most recent job in the previous year was in construction, suffered from an illness (long-standing and new cases) which was caused or made worse by their current job (HSE, 2013). A total of 818000 working days or $0 \cdot 4 \mathrm{~d}$ per worker in $2011 / 2012$ were lost owing to self-reported work-related illness (HSE, 2013).

In addition, the UK Health and Safety Executive has published figures that show that construction significantly exceeds the allindustry incidence rates with respect to musculoskeletal disorders, occupational dermatitis, work-related hearing loss, mesothelioma and asbestosis, with vibration-related disorders only being surpassed by the extractive industries (HSE, 2009). The economic and human costs related to occupational illnesses are substantial; for example, sickness absence costs the UK economy an estimated $£ 12$ billion a year (HSE, 2013). It is therefore essential that workers' occupational health is taken seriously and managed properly.

Younger workers (aged 15-24) make up 24\% of the construction workforce and, although they have a lower average risk of developing occupational illnesses than older workers, occupational illnesses often need cumulative exposure and/or a latency period to develop and may not always be recognised owing to short-term work contracts (ESAW, 2007). Protecting the health of younger workers is critical to the sustainability and long-term economic performance of the construction sector and also of great importance for the health and wellbeing of the young people themselves.

Table 1 shows the most prevalent ill-health conditions in construction (latest available data (HSE, 2009)). Other publications cover these conditions in considerable detail (e.g. Gibb et al., 1999 and McAleenan and Oloke, 2010). Diffuse pleural thickening, mesothelioma and asbestosis are all directly linked to historical asbestos exposure. Stress is also a significant ill-health issue for construction. Other than these, the main ill-health conditions are: musculoskeletal disorders (affecting upper limb, spine/back and hands), dermatitis, asthma and occupational deafness.

\section{Role of training for health and safety}

Training is a fundamental requirement for preventing occupational illnesses and improving the industry's occupational health performance, particularly for younger workers who are still developing their attitudes, skills and competencies (Nyateka et al., 2012). The provision of training by employers, along with 


\begin{tabular}{|c|c|c|c|c|}
\hline \multirow[b]{3}{*}{ Condition } & \multicolumn{4}{|c|}{ Average annual rate per 100000} \\
\hline & \multicolumn{2}{|c|}{ Hospital cases reported by specialist doctors } & \multicolumn{2}{|c|}{ Disablement benefits prescribed disease cases } \\
\hline & Construction & All industries & Construction & All industries \\
\hline Diffuse pleural thickening & 28.5 & 4.6 & $12 \cdot 8$ & 5.8 \\
\hline Mesothelioma & 14.5 & $2 \cdot 7$ & $44 \cdot 7$ & $2 \cdot 8$ \\
\hline Asbestosis & $2 \cdot 4$ & 0.6 & 21.7 & 1.4 \\
\hline All musculoskeletal disorders & 8.0 & $7 \cdot 0$ & 0.8 & $\mathrm{n} / \mathrm{a}$ \\
\hline Upper limb disorders & $6 \cdot 0$ & $5 \cdot 0$ & $\mathrm{n} / \mathrm{a}$ & $n / a$ \\
\hline Spine/back disorders & $1 \cdot 0$ & $1 \cdot 0$ & $\mathrm{n} / \mathrm{a}$ & 0.5 \\
\hline Vibration white finger & $1 \cdot 0$ & 0.4 & $6 \cdot 5$ & 0.8 \\
\hline Dermatitis & $6 \cdot 0$ & $6 \cdot 0$ & $1 \cdot 2$ & 0.7 \\
\hline Stress & $2 \cdot 0$ & $7 \cdot 0$ & $\mathrm{n} / \mathrm{a}$ & 1.5 \\
\hline Asthma & $1 \cdot 0$ & $1 \cdot 0$ & 0.9 & $0 \cdot 0$ \\
\hline Occupational deafness & $\mathrm{n} / \mathrm{a}$ & n/a & $2 \cdot 4$ & 0.9 \\
\hline
\end{tabular}

Table 1. Construction and 'all industries' ill-health data, 2005-2007 (adapted from HSE, 2009)

periodical refreshers, is an explicit requirement of the UK's health and safety legislation and research emphasises its importance (Burke et al., 2006; Dufficy, 2001, Linker et al., 2005; Loosemore et al., 2003; Mowlam et al., 2010).

Inadequate or lack of, occupational health training has been identified as an important contributing factor to the high incidence rates within the industry (Guo et al., 2012; Tam and Fung, 2011; Wallen and Mulloy, 2006).

\section{Effectiveness of participative techniques}

Much conventional learning practice, including most construction training courses, tends to focus on abstract knowledge over actual practice, relying particularly on traditional trainercentred approaches (Nyateka et al., 2014). Workers are typically sat down in a classroom-like setting and spoken to by 'experts' supported by PowerPoint, booklets and videos and are then expected to apply this abstracted knowledge later in the workplace (Gherardi and Nicolini, 2002). These approaches isolate knowledge from practice and are often ineffective owing to a failure to actively engage learners; the emphasis on auditory learning as opposed to styles such as visual or tactile learning; the assumption that all trainees learn at the same pace and have similar levels of understanding; and the risk of information loss owing to their passive nature (Piercy et al., 2012).

Many education experts emphasise the way that knowledge is socially situated, particularly the role that activity, participation and experience play in learning (Abdulwahed and Nagy, 2009; Goedert et al., 2011; Pasin and Giroux, 2011; White, 2010). Experiential learning occurs when 'knowledge is created through the transformation of experience' (Kolb, 1984). Experiential training methods are increasing, albeit mainly in non-construction contexts (DeshPande and Huang, 2011; Li et al., 2007; Mawdesley et al., 2011; Piercy et al., 2012). Learning by doing distinguishes experiential learning from passive learning using traditional classroom-based lectures. Examples include simulations, role-plays, laboratories, fieldwork and live cases (Hawk and Shah, 2007). Piercy et al. (2012) argue that experiential teaching has strengths including

- active engagement of trainees in their own learning

- stimulation of interest in the subject

- opportunity to learn how to work in often diverse groups

- acquisition of high-order skills (teamwork, communication, conflict resolution, presentation)

- application of theory to practice

- trying out ideas in a safe environment.

Recent literature highlights the need to embrace new ways of learning, actively engaging the learner (DeshPande and Huang, 2011; Goedert et al., 2011; Mawdesley et al., 2011). Goedert et al. (2011) argue that simulation-based learning addresses the fundamental need to reinvigorate training methods and approaches in construction, which 'have changed little in over a century'.

An innovative mechanism for increasing understanding is by empathic modelling 'whereby an individual, using various props and scenarios, is able to simulate the deterioration of physical and

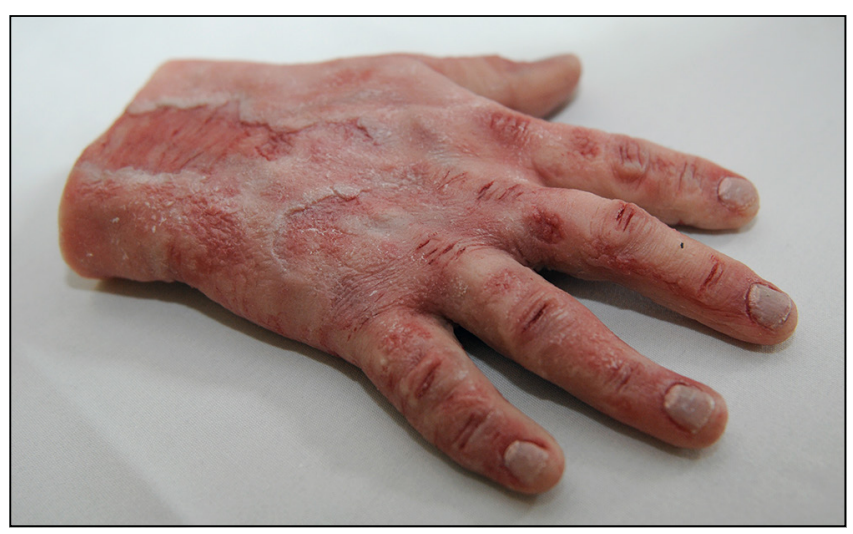

Figure 1. LUSKInS dermatitis glove 


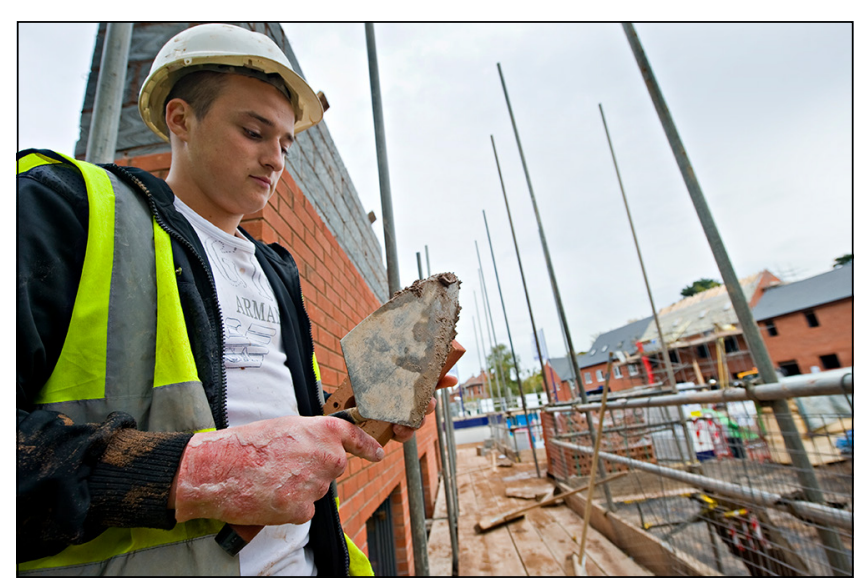

Figure 2. Dermatitis glove worn by an apprentice bricklayer

perceptual abilities in everyday scenarios' (Nicolle and Maguire, 2003). The Loughborough University sensory kinesthetic interactive simulations (LUSKInS) can be worn by those without particular illhealth conditions to enable them to directly experience for themselves something of what it feels like to suffer the condition (Figures 1 and 2).

\section{Development of wearable simulations}

\subsection{Previous research and developments}

The authors have been researching into occupational health in construction since the early 1990s (e.g. Gyi et al., 1998). The focus on ageing in construction grew from a broader interest in vulnerable workers, which had previously focused on migrant labour. This ageing-related research began in 2006 with research funding from Sparc, the research councils' pump-priming initiative for strategic promotion of ageing-related research (e.g. Gibb et al., 2013). This was followed in 2008-2012 by work with the 'New dynamics of ageing' programme, a multidisciplinary research initiative to ultimately improve the quality of life of older people (e.g. Yolande Williams et al., 2011). Other ongoing work includes doctoral research funded by Age-UK, investigating construction workplace design to help people to work more healthily for longer, should they choose to (e.g. Eaves et al., 2014).

Alongside the research stream, Loughborough University has also been active in the design and application of wearable simulations for 20 years, building upon the development of its first whole-body simulation of ageing, namely the 'third age suit', in 1994. This was developed for the Ford Motor Company to raise awareness of the needs of older drivers among the predominantly young design team, leading to more empathically designed vehicles (Hitchcock et al., 2001). A simulation of osteoarthritis was subsequently commissioned by Napp Pharmaceuticals to increase the prominence and understanding of the condition within the medical profession. This was later purchased by Stannah Stairlifts to improve the appreciation of osteoarthritis within their sales and designs teams.

The simulations have also been employed in Europe, North and South America, Asia and Australia and across a range of domains (automotive, aerospace, architecture, health, finance, mobility, education and public engagement), always with the underlying aim of changing attitudes and behaviour through improved awareness. One reason for the success of the simulations is their contribution to the experiential learning process and, given the need for a stronger focus on occupational health within construction, it was considered that this approach could significantly contribute to training in this area.

\subsection{LUSKInS development}

Cook et al. (2009, 2012) have covered the evidencebased development of the LUSKInS, which was funded by the Engineering and Physical Sciences Research Council. A comprehensive literature review and interviews with health professionals developed an appreciation of the health conditions based upon observations across a range of patients. Interviewees either had specific knowledge of construction occupational health or were specialists in the particular health conditions. Interviews with workers with the conditions added detailed, personal experiences. These complementary methods provided a data-rich underpinning to the research. Data were collated and analysed as follows

- description, symptoms, severity progression, frequency, impact and severity measures - used to inform the simulation design

- causes, risk, industry prevalence, aggravating factors, avoidance and treatment - used to provide context/rationale for the simulations.

A specification was developed and reviewed by specialist health professionals covering mild, moderate and severe forms of the five health conditions using these refined data. This research progressed beyond simulations developed solely from subjective data to those underpinned by objective measures; for example, objective data relating to noise-induced hearing loss are provided in Table 2.

Development of the simulations was a creative, iterative process, driven by the specification requirements and encompassing additional important design considerations including: goodness of fit; ethics; cost; materials and technology; durability; and hygiene. As well as identifying items which would deliver the 'symptomatic' requirements of the simulations, further components were required to maintain these items in the appropriate position relative to the wearers' body, such as gloves to which symptomatic elements for dermatitis and hand-arm vibration syndrome were secured (Figure 3).

\begin{tabular}{|c|c|c|c|}
\hline & \multicolumn{3}{|c|}{ Symptoms - level of severity } \\
\hline & Mild & Moderate & Severe \\
\hline $\begin{array}{l}\text { Noise-induced hearing loss } \\
\text { (objective data) }\end{array}$ & $\begin{array}{l}\text { Selective hearing loss (around } 4000 \mathrm{~Hz} \text { ) } \\
\text { - only some words are missed } \\
\text { Hearing loss at } 21-40 \mathrm{~dB}(40 \mathrm{~dB} \\
\text { equivalent to talking in a quiet voice) }\end{array}$ & $\begin{array}{l}\text { Hearing loss progresses to middle } \\
\text { frequencies }(3000-6000 \mathrm{~Hz}) \text {. Hearing } \\
\text { loss at } 41-70 \mathrm{~dB}\end{array}$ & $\begin{array}{l}\text { High-frequency hearing lost, } \\
\text { low-frequency hearing impaired } \\
\text { (500-2000 Hz) } \\
\text { Hearing loss at 71-95 dB }\end{array}$ \\
\hline
\end{tabular}

Table 2. Occupational health specification for noise-induced hearing loss 


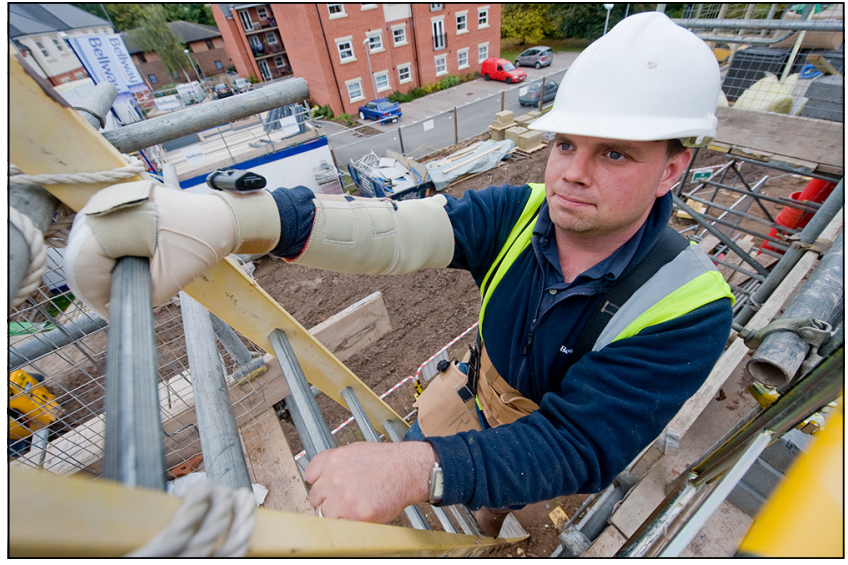

Figure 3. Worker climbing ladder wearing upper-limb disorders and hand-arm vibration syndrome simulations

Developmental workshops explored the extent to which the candidate items delivered the desired effect in a safe manner. For instance, itching powder to simulate dermatitis, while meeting the specification, was excluded owing to a potential adverse reaction. The items were then further screened for inclusion against: goodness of fit; cost; anticipated robustness; ease of fitment/ attachment within the simulation; and hygiene. The prototyping stage combined the individual items into an integrated simulation.

Previous simulations were only concerned with conveying the overall sensory aspects of the symptoms. However, with dermatitis, the psychological impact is also significant. For example, some sufferers had a restricted social life because they were too embarrassed to go out. Therefore, photographs and diagrams of dermatitis at mild, moderate and severe levels were provided to a special effects film modeller who produced gloves for each severity level.

The glove format for the visual simulation was chosen to offer most realism to the wearer. However, there were problems in the glove's development, including the need to incorporate sufficient elasticity to accommodate a range of sizes since, traditionally, such work is bespoke to a specific actor. In addition, each glove was hand-finished and therefore costly, so the hand-arm vibration syndrome visual simulations were made as solid three-dimensional silicone models.

A digital-based system offered greatest flexibility and highest fidelity for noise-induced hearing loss for the shape, number and accuracy of the audiograms. However, this approach was rejected on cost grounds and a simplified, linear system employing a number of fixed filters was adopted. This had audio inputs by way of a lapel-microphone, channelled through a selected filter, then delivered directly by way of earphones.

The prototype struggled to represent the full impacts of the condition owing to the direct conductance of external sounds, including the speaker's voice, through the skull and foam eartips, by passing the attenuator. Therefore, the final solution replaced the face-to-face conversation with a mobile phone conversation so the speaker could be in a different room from the hearer.

\section{Applying research outputs in industry}

The National Construction College and the Health and Safety Executive reviewed the simulations as awareness raisers and identified design improvements. One training expert commented that, 'representation of the symptoms cannot be presented in any other way - there is a huge potential benefit for the industry'. The college agreed to a trial application to determine their effectiveness in driving attitudinal change in younger workers.

The college is the largest training provider in Europe providing courses for new entrants to construction. The trial, involving construction apprentices in various trades including scaffolding, roofing, steeplejacks and plant operators, comprised

- a preliminary attitudinal survey at the start of the first training course $(n=161)$

- video-recorded and field-noted observations of existing courses, without LUSKInS (control sample) $(n=91)$

- video-recorded and field-noted observations of courses implementing the simulations $(n=70)$

- a follow-up survey at the end of the first course: trainees not using LUSKInS (control sample) $(n=50)$; trainees experiencing LUSKInS $(n=62)$

- in-depth recorded interviews with experienced trainers/health and safety practitioners $(n=9)$ and trainees $(n=16)$.

The majority (58\%) of the apprentices were aged 21 years and under, $27 \%$ were between 22 and 24 and $15 \%$ were over 25 . Despite this being their first industry training course, $79 \%$ said they had already received some health and safety training, with most citing either school or site inductions. However, most of this prior training (73\%) had been non-interactive 'lectures' or formal tasks. DVDs (61\%) and booklets (39\%) had been used, while $22 \%$ indicated some use of more hands-on approaches.

The findings support previous studies (Deshpande and Huang, 2011; Gherardi and Nicolini, 2002), finding that classroom-based lectures remain the dominant training method in construction. Regarding the apprentices, $83 \%$ preferred highly active learning environments and engaging methods, even though previously they had not experienced these much. This is not surprising since, by choosing the apprenticeship route, they had chosen to leave the more academic environment of post-16 schooling. The findings about methods of training support Mowlam et al. (2010) and Goedert et al. (2011), who found a preference among young learners for interactive and innovative learning methods.

During the session observations, the researcher took field notes, comprising phrases, key words and quotes as well as sketches of the room and position of the participants. Full field notes provided a log of observations as well as recording the researcher's impressions and feelings.

It is notoriously difficult to obtain rigorous data regarding attitudinal or behavioural change as a result of interventions. A multiple baseline approach (e.g. Lingard and Rowlinson, 1998) was not possible in this case, but is planned for future trials. Notwithstanding, the application to date has clearly showed that the apprentices were far more engaged when using or observing the simulations, and their verbal feedback strongly supports the view that their understanding has grown and their attitudes towards health issues have changed for the better (Figures 4 and 5).

Quotes from trainees included: 'Once I'm doing something practical, I remember it much easier'; 'I get a better understanding with a more hands-on approach to learning'; 'I get bored with handbooks and lectures'; 'Engaging keeps people alert and focused'; 'I don't take in things from reading or being told, it's 


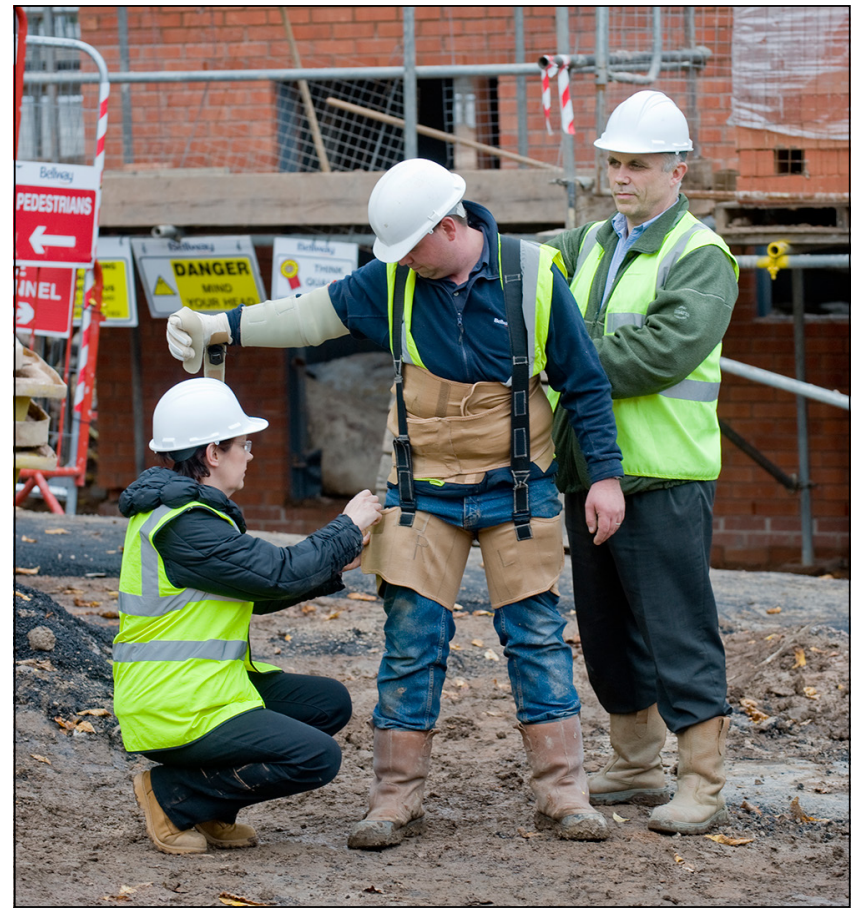

Figure 4. Musculoskeletal disorder and hand-arm vibration syndrome simulations being applied

easier for me to watch and try out'; and 'I concentrate and learn more with engaging methods and training is enjoyable'.

The simulations definitely engaged the trainees and stimulated considerable discussion; for example: 'A lot of the older lads, they've got that now (hearing problems). I sound like a bit of a geek because I always put my ear plugs in ... obviously as a 50 year old you don't want to be going 'eh?' - That's how they do it'; 'You couldn't work like that (with severe hand-arm vibration syndrome)... especially what we're doing, working at height, if you can't grab something properly you could drop it and kill someone'; 'I've got 'girly' hands, me, and I'm staying that way' (commenting on the dermatitis gloves); and 'You're pressured to get on with the job and you do it. You're standing there with loads of people around you saying: 'Come on!' Your supervisor is there saying: 'Come on guys!' So you just grab something and do it' (discussing manual handling while watching a classmate wearing the musculoskeletal disorder simulation).

\subsection{Demonstration of hearing loss}

The noise-induced hearing loss demonstration required an apprentice to listen to music channelled from his phone through the noise-induced hearing loss equipment. They were asked to tell the group what they were experiencing as the settings were changed to simulate mild, moderate and finally severe noise-induced hearing loss conditions.

Observing a classmate using the simulation, another worker realised that he had a problem with his hearing. 'My girlfriend accuses me of having selective hearing and I have to turn the television up very loud'.

Apparently on his site, a number of the older workers did not wear ear defenders and had difficulty hearing. His work involved

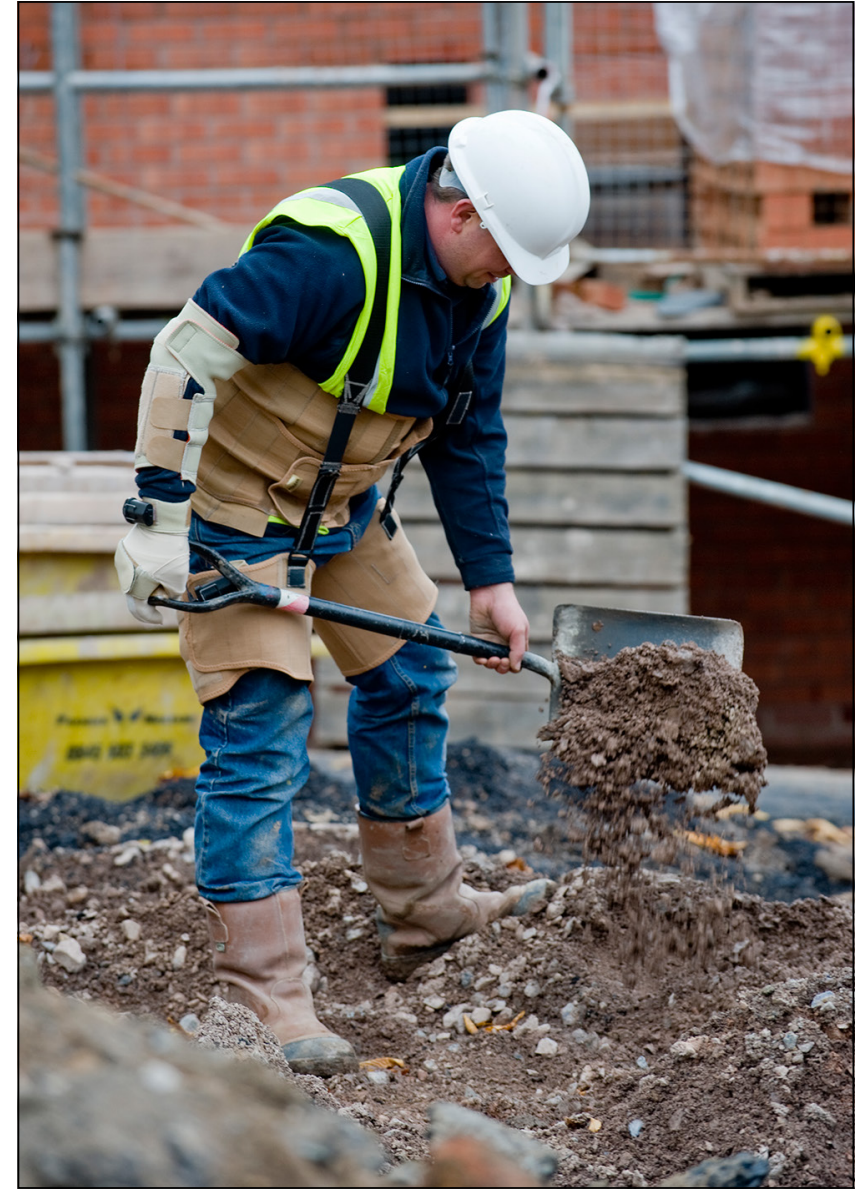

Figure 5. Musculoskeletal disorder and hand-arm vibration syndrome simulations in action on site

applying fixings to a building using hand-held power tools close to his head and he had not been wearing any hearing protection. He had been told by the other workers to, 'Man-up for a couple of weeks and you'll get used to it'.

He had not previously made a connection between the work and hearing problems of his fellow workers until the demonstration but was now determined to get his hearing checked and wear the personal protective equipment. The discussion then opened up on the importance of speaking out against practices with risks to workers' health.

\section{Implications for civil engineers and construction managers}

Research into age-exacerbated, occupational ill-health conditions in construction is continuing and yet workers are still behaving as if they were invincible and as if their bodies were immune to the combined effects of a harsh construction environment and the natural ageing process.

The message is not penetrating the workforce, despite the increase in training and site inductions. More of the research needs to be made relevant to practice. In this case, the researchers 
have taken findings beyond theory and developed wearable simulations.

The effectiveness of these simulations is being evaluated in the context of seeking to drive attitudinal change in young apprentices, hopefully to motivate them to play their part in reducing the likelihood that they will develop these conditions. More work is needed, but this is an encouraging start.

\section{Acknowledgements}

The authors acknowledge particular input to this research from Karen Walmsley, John Richardson and Andrew Dainty. In addition, they recognise the important role of the many representatives from construction organisations, training companies and occupational health practices and the several funding bodies that have supported this research.

\section{References}

Abdulwahed M and Nagy ZK (2009) Applying Kolb's experiential learning cycle for laboratory education. Journal of Engineering Education 98(3) 283-294.

Burke MJ, Sarpy SA, Smith-Crowe K, Chan-Serafin S, Salvador RO and Islam $G$ (2006) Relative effectiveness of worker safety and health training methods. American Journal of Public Health 96(2): 315-324.

Cook S, Richardson J, Gibb AGF and Bust PD (2009) Raising awareness of the occupational health of older construction workers. In Proceedings of $C I B$ W099 International Conference, Melbourne, Australia (Lingard H (ed.)), RMIT, Melbourne, pp. 33-43.

Cook S, Gibb AGF, Richardson J, Walmsley K and Bullock D (2012) Loughborough University SKInS: wearable simulations of occupational health - defining specifications and product development. In Proceedings of CIB WO99 International Conference, Singapore, NUS (Tao E (ed.)), NUS, Singapore, pp. 358-367.

DeshPande AA and Huang SH (2011) Simulation games in engineering education: a state-of-the-art review. Journal of Computer Applications in Engineering Education 19(3): 399-410.

Dufficy M (2001) Training for success in a new industrial world. Industrial and Commercial Training 33(2): 48-53.

Eaves S, Gyi DE and Gibb AGF (2014) Healthy construction workers by better workplace design. In Proceedings International Conference cib W099 - Achieving Sustainable Construction Health and Safety, Lund, Sweden (Aulin R and Ek Å (eds)), Lund University, Lund, Sweden, pp. 148-156.

ESAW (European Agency for Safety and Health at Work) (2007) OSH in Figures: Young Workers - Facts and figures. ESAW, Brussels.

Gherardi S and Nicolini D (2002) Learning the Trade: A Culture of Safety in Practice. Sage Publications, London, UK.

Gibb AGF Gyi DE and Thompson T (1999) The ECl Guide to Managing Health in Construction. Thomas Telford, London, UK.

Gibb AGF, Leaviss J and Bust PD (2013) Older construction workers: needs and abilities. In Proceedings of the 29th Annual ARCOM Conference, Reading, UK (Smith SD and Ahiaga-Dagbui DD (eds)). Association of Researchers in Construction Management, Reading, pp. 261-271.

Goedert J, Cho Y, Subramaniam M, Guo H and Xiao L (2011) A framework for virtual interactive construction education (VICE). Automation in Construction 20(1): 76-87.

Guo H, Heng L, Chan G and Skitmore M (2012) Using game technologies to improve the safety of construction plant operations. Accident Analysis and Prevention 48: 204-213.

Gyi DE, Gibb AGF and Haslam RA (1998) Case studies of occupational health management in the engineering construction industry. Occupational Medicine 48(4): 263-271.
Hawk TF and Shah AJ (2007) Using learning style instruments to enhance student learning. Sciences Journal of Innovative Education 5(1): 1-19.

Hitchcock D, Lockyer S, Cook S and Quigley C (2001) Third age usability and safety: an ergonomics contribution to design. International Journal of Human-Computer Studies 55(4): 635-643.

HSE (Health and Safety Executive) (2009) See http://www.hse.gov.uk/ statistics/industry/construction/index.htm (accessed 01/07/2009).

HSE (2013) Construction: Work Related Injuries and III Health. HSE, London, UK. See www.hse.gov.uk/statistics/industry/construction/construction.pdf (accessed 05/08/2013).

Kolb D (1984) Experiential Learning: Experience as the Source of Learning and Development. Prentice-Hall, Englewood Cliffs, NJ, USA.

Li T, Greenberg BA and Nicholls JAF (2007) Teaching experiential learning: adoption of an innovative course in an MBA marketing curriculum. Journal of Marketing Education 29(1): 25-33.

Lingard $\mathrm{H}$ and Rowlinson (1998) Behaviour-Based Safety Management in Hong Kong's Construction Industry: The Results of a Field Study, HKU Scholars Club, Hong Kong University.

Linker D, Miller M, Freeman K and Burbacher T (2005) Health and safety awareness for working teens: developing a successful, state-wide program for educating teen workers. Family Community Health 28(3): 225-238.

Loosemore M, Dainty, ARJ and Lingard H (2003) Human Resource Management in Construction Projects: Strategic and Operational Approaches. Spon Press, London UK.

Mawdesley M, Long G, Al-jibouri S and Scott D (2011) The enhancement of simulation based learning exercises through formalised reflection, focus groups and group presentation. Computers and Education 56(1): 44-52

McAleenan C and Oloke D (2010) ICE Manual of Health and Safety in Construction - Assessing Health Issues in Construction. Thomas Telford, London, UK.

Mowlam A, Mitchell M, Jones N and Ludford H (2010) How Best to Communicate Health and Safety Messages to Young Learners in Vocational Education and Training. Health and Safety Executive, London, UK.

Nicolle C and Maguire M (2003) Empathic modelling in teaching design for all. In Proceedings of International Conference on Human-Computer Interaction: Inclusive Design in the Information Society. See https:/l dspace.lboro.ac.uk/dspace-jspui/bitstream/2134/722/1/PUB184\%20 Empathic\%20Modelling.pdf (accessed 16/06/2015), HCl, Crete, Greece.

Nyateka N, Dainty ARJ, Gibb AGF and Bust PD (2012) Evaluating the role and effectiveness of training interventions in improving the occupational health and safety of younger construction workers: a literature review. In Proceedings of 28th Annual ARCOM Conference, Edinburgh, Association of Researchers in Construction Management (Smith SD (ed.)), Reading, pp. 455-464.

Nyateka N, Gibb AGF, Dainty ARJ, Bust PD and Cook S (2014) The role of simulation-based learning in the occupational health training of younger construction workers. In Proceedings International Conference CIB W099 - Achieving Sustainable Construction Health and Safety, Lund, Sweden (Aulin R and Ek Å (eds)), Lund University, Lund, Sweden, pp. 38-49.

Pasin $F$ and Giroux $H$ (2011) The impact of a simulation game on operations management education. Computers and Education 57(1): 1240-1254.

Piercy N, Brandon-Jones A, Brandon-Jones E and Campbell C (2012) Examining the effectiveness of experiential teaching methods in small and large OM modules. International Journal of Operations and Production Management 32(12): 1473-1492.

Tam VWY and Fung IWH (2011) Tower crane safety in the construction industry: a Hong Kong study. Safety Science 49(2): 208-215.

Wallen ES and Mulloy KB (2006) Computer-based training for safety: comparing methods with older and younger workers. Journal of Safety Research 37(5): 461-467.

White C (2010) A socio-cultural approach to learning in the practice setting. Nurse Education Today 30(8): 794-797.

Yolande Williams E, Gyi DE, Gibb AGF and Haslam RA (2011) Ageing productively through design?: a survey of cement manufacturing workers. The International Journal of Ageing in Society 1(4): 1-18. 